\title{
Performance of Distress Thermometer and Associated Factors of Psychological Distress among Chinese Cancer Patients
}

\author{
Sudip Thapa, ${ }^{1}$ Huihui Sun, ${ }^{1}$ Gaurab Pokhrel, ${ }^{2}$ Bangyan Wang, ${ }^{1}$ Sanuja Dahal, ${ }^{3}$ \\ and Shiying Yu ${ }^{1}$ \\ ${ }^{1}$ Cancer Center of Tongji Hospital, Tongji Medical College, Huazhong University of Science and Technology, \\ Wuhan 430030, China \\ ${ }^{2}$ Department of Urology, Tongji Hospital, Tongji Medical College, Huazhong University of Science and Technology, \\ Wuhan 430030, China \\ ${ }^{3}$ School of Nursing, Tongji Medical College, Huazhong University of Science and Technology, Wuhan 430030, China \\ Correspondence should be addressed to Shiying Yu; syyu_tjh@163.com
}

Received 30 May 2020; Revised 10 September 2020; Accepted 12 September 2020; Published 22 September 2020

Academic Editor: Nihal Ahmad

Copyright (C) 2020 Sudip Thapa et al. This is an open access article distributed under the Creative Commons Attribution License, which permits unrestricted use, distribution, and reproduction in any medium, provided the original work is properly cited.

\begin{abstract}
Objective. We aimed to examine the performance of the distress thermometer (DT) and identify the prevalence and risk factors associated with psychological distress (PD) in heterogeneous cancer patients. Methods. This cross-sectional study enrolled 1496 heterogeneous cancer patients from the inpatient and outpatient departments. Receiver operating characteristic analysis (ROC) of DT was evaluated against the Hospital Anxiety and Depression Scale-Total (HADS-T $\geq 15$ ). An area under the curve (AUC), sensitivity, specificity, positive predictive value (PPV), negative predictive value (NPV), and clinical utility index were calculated. Multiple binary logistic regression was used to identify the factors associated with PD. Results. Referring to ROC analysis, DT showed good discriminating accuracy (AUC $=0.88$ ). A cutoff score of 4 was established, and it yielded sensitivity $(0.81)$, specificity (0.88), PPV (0.87), NPV (0.82), and clinical utility indexes (screening utility $=0.71$ and case-finding utility $=0.73$ ). $46.5 \%$ of our participants was distressed. Lower education levels (odd ratio $(\mathrm{OR})=1.39)$, advanced stage $(\mathrm{OR}=1.85)$, active disease status $(\mathrm{OR}=1.82)$, lack of exercise $(\mathrm{OR}=3.03)$, diagnosis known $(\mathrm{OR}=0.64)$, emotional problems $(\mathrm{OR}=3.54)$, and physical problems $(\mathrm{OR}=8.62)$ were the predictive factors for PD. Conclusion. DT with a cutoff score $(\geq 4)$ is a comprehensive, appropriate, and practical initial screener for PD in cancer patients. Predicting factors should be considered together for effective management of $\mathrm{PD}$ in such population.
\end{abstract}

\section{Introduction}

Anxiety and depression are common after a cancer diagnosis. Though anxiety and depression are different clinical entities, they are generally referred to as psychological distress (PD). Cancer-related PD has profound negative impacts on patients' health as it is associated with poor quality of life [1], poor satisfaction with medical treatments [2], and suicidal ideation [3]. Timely identification and treatment of $\mathrm{PD}$ are beneficial in reducing its negative consequences among cancer patients [4]. Therefore, the National Comprehensive Cancer Network (NCCN) Guidelines for Distress Management recommend that every cancer patient should be screened for PD and managed accordingly [5].

Screening is defined as the presumptive identification of unrecognized disease. Screening tool is an initial investigation of a disease or condition. There are various screening tools for PD such as the Hospital Anxiety and Depression Scale (HADS), Brief Symptom Inventory-18 (BSI-18), Symptom Checklist-90, and other psychiatric interview tools. These tools are lengthy, time-consuming, and bothersome for patients to complete. Therefore, the NCCN Distress Management Panel and available studies recommend the use of the distress thermometer (DT) as a screening tool for PD. The DT is ultrashort, easy to use, and 
nonstigmatizing for the patients [5-7]. DT is valid in many countries, and its recommended cutoff score is $4[8,9]$. However, its area under the ROC curve (AUC $=0.47-0.91$ ), sensitivity $(\mathrm{SE}=0.42-1.00)$, specificity $(\mathrm{SP}=0.36-0.98)$, positive predictive value $(\mathrm{PPV}=0.23-0.95)$, negative predictive value (NPV $=0.68-0.97)$, and the optimal cutoff score (3-7) vary among different countries, studies, clinical settings, cancer types, and patients' sociodemographic characteristics [8-15].

In China, cancer is a common public health burden, and caring cancer patients is commonly troublesome by nondisclosure of the diagnosis [16]. Even patients who knew their diagnosis often keep a secret because they are influenced by their philosophical and medical beliefs [17]. This could lead to inaccurate expressions of their feelings about the diagnosis and the level of their perceived distress. Over the past decades, education and health care facilities in China have improved significantly. These improvements have brought knowledge, awareness, and acceptance of cancer. Interestingly, a recent study has shown that there is an increasing trend in the disclosing of diagnosis in Chinese cancer patients [18]. Thus, the significance of validating DT in recent time remains very important. DT performance in China differs with geographic locations from poor to excellent, and its cutoff scores vary between 3 and 5 $[11,12,19-22]$. To date, most of the Mainland Chinese studies only measured the accuracy of DT against specific cancer types. Available studies (Table 1) are limited by clinical settings (inpatient) and insufficient study population that may not effectively represent the overall cancer population [12, 20-24]. This raises the question as to whether one comprehensive optimal cutoff score to distinguish PD in general cancer patients regardless of the clinical setting (inpatient and outpatient) and cancer types is needed. Thus, this study aimed to (1) evaluate the performance and determine a comprehensive DT cutoff score to measure PD in heterogeneous cancer patients and (2) investigate the prevalence and factors associated with PD in these populations.

\section{Methods}

2.1. Participants. This cross-sectional study was conducted from July 2018 to January 2019 in the inpatient and outpatient departments of the Cancer Center of Tongji Hospital, Tongji Medical College, Huazhong University of Science and Technology. The inclusion criteria included: age $>18$ years, literate with normal cognitive functions, diagnosed with cancer, and willing to participate. Informed consent was obtained from the eligible participants and were requested to complete the questionnaire by themselves or with the help of a research assistant. Patients with a history of psychiatric illness were excluded from this study. A questionnaire including sociodemographic information such as age, sex, marital status, education level, occupation, monthly income, aware/unaware of diagnosis, and exercise habit was distributed to each participant. Exercise habit was categorized into 2 groups: frequent exercise (>150 min/week) and lack of exercise ( $<150 \mathrm{~min} /$ week). Clinical information such as disease status, duration, stage and type of cancer, and treatment received were collected from the computer records.

This study was a part of a clinical trial which was approved by the Research Ethical Board of Tongji Medical College (CFDA\#2015R006398), and the Declaration of Helsinki was strictly followed.

2.2. Measurements. DT is a single item, self-reported, thermometer-shaped visual analog scale consisting of 11 points ranging from 0 (no distress) to 10 (extreme distress) that measures PD over the past 7 days. The problem list (PL) recommended by NCCN is used to identify the nature of the possible problems that cause PD. It contains a list of 36 possible problems that are categorized in 5 domains (practical, family, emotional, physical problems, and spiritual or religious concerns), but the Chinese version of $\mathrm{PL}$ contains 40 possible problems. DT accompanied with $\mathrm{PL}$ is a validated tool in China [19].

HADS is widely used for defining the presence of cancerspecific mood disorders. HADS is a 14 item self-rated screening tool. It includes anxiety (HADS-A) and depression (HADS-D) subscales, and each subscale contains 7 items [25]. Clinically, the two subscales of HADS (HADS-A and HADS-D) considered a single measurement of HADS-T (PD). As a screening tool, HADS has good accuracy and validity [26]. Most of the studies have used HADS as a standard criterion for validating DT $[8,9]$, and many studies have considered HADS-T $\geq 15$ as a cutoff score for $\mathrm{PD}$ $[8,9,15,22]$.

2.3. Statistical Analysis. The receiver operating characteristic (ROC) curve analysis was performed to identify the cutoff score of DT against the HADS-T $\geq 15$. Youden index (i.e., sensitivity + specificity-1) was calculated, and its largest value determines the optimal cutoff score. The AUC was used to measure the overall discriminative accuracy of DT against the HADS-T, and the value of $0.5-0.7,0.7-0.9$, and $\geq 0.9-1.0$ reflected low, moderate, and excellent discriminative accuracy, respectively.

The SE, SP, PPV, and NPV were evaluated at each DT cutoff score against the HADS-T. Interpretation of screening tests can be improved by clinical utility index (UI) as it gives more information about the performance of the screening tool [27] and was also applied in our study. SE and SP are measures of occurrence, while PPV and NPV are measures of discrimination. The positive utility index $(\mathrm{UI}+)=\mathrm{SE} \times \mathrm{PPV}$ provides rule-in accuracy (case-finding), and negative utility index $(\mathrm{UI}-)=\mathrm{SP} \times \mathrm{NPV}$ provides ruleout accuracy (screening) of the test [27]. Furthermore, the main factors contributing to PD was identified using multiple binary logistic regression model analysis. The statistical package for social science (SPSS, version 20.0, Chicago, IL, USA) was used to analyze the data, and a value of $P \leq 0.05$ was considered to be statistically significant. 
TABle 1: Summary of the Mainland China and Taiwan studies examining the validity of the distress thermometer (DT).

\begin{tabular}{|c|c|c|c|c|c|c|c|c|c|c|c|}
\hline Author & Origin & $\begin{array}{l}\text { Sample } \\
\text { size }\end{array}$ & Cancer type & Setting & $\begin{array}{c}\text { Reference } \\
\text { criteria }\end{array}$ & $\begin{array}{l}\text { DT cutoff } \\
\text { score }\end{array}$ & AUC & SE & $\mathrm{SP}$ & PPV (\%) & NPV (\%) \\
\hline Tang et al. & & & & & HADS-T & 4 & 0.80 & 0.80 & 0.70 & & \\
\hline$[19]^{\circ}$ & Beijing & 574 & Mixed & Inpatient & SCL-90 & 4 & 0.83 & 0.87 & 0.72 & & \\
\hline $\begin{array}{l}\text { Hong et al. } \\
{[20]}\end{array}$ & Fujian & 442 & NPC survivors & & HADS-T & 4 & 0.72 & 0.42 & 0.85 & & \\
\hline $\begin{array}{l}\text { Deng et al. } \\
{[21]}\end{array}$ & Sichuan & 295 & NPC & & HADS-T & 4 & 0.87 & 0.73 & 0.85 & 69.0 & 87.0 \\
\hline $\begin{array}{l}\text { Wang et al. } \\
\text { [12] }\end{array}$ & Sichuan & 323 & Lymphoma & Inpatient & HADS-T & 5 & 0.91 & 0.75 & 0.86 & & \\
\hline Zheng et al. & Sichuan & 172 & & Innatient & HADS-T & 4 & 0.91 & 0.82 & 0.95 & & \\
\hline$[11]$ & Sichuan & 172 & & Inpatient & HADS-T & 3 & 0.79 & 0.78 & 0.79 & & \\
\hline $\begin{array}{l}\text { Guan et al. } \\
\text { [22] }\end{array}$ & Tianjin & 441 & $\begin{array}{l}\text { Advance mixed cancer } \\
\text { patients with pain }\end{array}$ & Inpatient & HADS-T & 5 & 0.75 & 0.86 & 0.53 & 73.6 & 71.5 \\
\hline $\begin{array}{l}\text { Wang et al. } \\
{[23]}\end{array}$ & Taiwan & 103 & Mixed & & DSM IV & 4 & 0.89 & 0.98 & 0.73 & & \\
\hline $\begin{array}{l}\text { Chiou et al. } \\
\text { [24] }\end{array}$ & Taiwan & 786 & Mixed & Inpatient & GHQ-12 & 4 & 0.79 & 0.72 & 0.80 & 29.2 & 96.2 \\
\hline
\end{tabular}

NPC, nasopharyngeal cancer; HADS-T, Hospital Anxiety and Depression Scale-Total; SCL-90, Symptom Checklist-90; DSM IV, Diagnostic and Statistical Manual of Mental Disorders, 4th edition; GHQ-12, General Health Questionnaire-12; AUC, area under the curve; SE, sensitivity; SP, specificity; PPV, positive predictive value; NPV, negative predictive value.

\section{Results}

3.1. Demographic and Clinical Characteristics. A total of 1518 patients were approached, $22(1.5 \%)$ denied their participation, and 1496 (98.5\% response rate) were included in the final analysis, of which 784 were inpatient and 712 outpatient. The mean age of patients was $54.4 \pm 11.2$ years. Among the total participants, $51.3 \%$ was female, $56.6 \%$ attended junior high school or below education, and $67.5 \%$ lacked regular exercise. Regarding clinical characteristics, $80.7 \%$ had noncomplete remission (active disease status), $89.9 \%$ knew their diagnosis, $38.5 \%$ had stage IV cancer, $55.7 \%$ received combined treatment, $33.6 \%$ had lung cancer, and followed by digestive cancer $27.7 \%$ (Table 2).

3.2. Descriptive Statistics of Psychological Distress on Problem List Domains. The mean score of DT was $3.3 \pm 2.6$. At DT $(\geq 4), 46.5 \%(n=696)$ of participants was found to be distressed. The reported major sources of distress were physical problems $(n=1174,78.5 \%)$ followed by emotional problems $(n=1064,71.1 \%)$, practical problems $(n=894,59.8 \%)$, family problems $(n=464,31.0 \%)$, and spiritual problems $(n=12,0.8 \%)$ (Table 2).

3.3. ROC Analysis and Optimal Cutoff Score. DT showed a good discriminating accuracy $(\mathrm{AUC}=0.88,95 \%$ CI 0.865-0.901) between distress and nondistress against HADS-T $\geq 15$. A cutoff score of 4 on DT correctly identified 0.81 of HADS distress cases (SE) and 0.88 of HADS nondistress cases (SP) with PPV (i.e., proportions of detecting true positives) and NPV (i.e., proportions of detecting true negative) of 0.87 and 0.82 , respectively. The UI calculation demonstrated that DT had good accuracy in both screening $(\mathrm{UI}+=0.71)$ and case-finding (UI- $=0.73)$ (Figure 1 and Table 3).
3.4. Factors Influencing Distress. Multiple binary logistic regression analysis revealed that lower education levels $(\mathrm{OR}=1.39, P=0.01,95 \%$ CI $1.060-1.825)$, active disease status $(\mathrm{OR}=1.82, P=0.001,95 \% \mathrm{CI} 1.274-2.619)$, advanced cancer stage $(\mathrm{OR}=1.85, P<0.001,95 \% \mathrm{CI} 1.424-2.405)$, lack of exercise $(\mathrm{OR}=3.03, P<0.001,95 \% \mathrm{CI} 2.307-3.989)$, emotional problems $(\mathrm{OR}=3.54, \quad P<0.001,95 \% \quad \mathrm{CI}$ 2.540-4.942), and physical problems $(\mathrm{OR}=8.62, P<0.01$, 95\% CI 5.468-13.594) were the risk factors for PD. Whereas patients who knew their diagnosis $(\mathrm{OR}=0.64, P=0.02,95 \%$ CI 0.435-0.951) were not likely to be at risk of PD (Table 4).

\section{Discussion}

In cancer care, PD is considered as the "Sixth Vital sign" [28]. A generalized, efficient, and accurate screening tool is needed for timely identification and proper management of distressed patients. To the best of our knowledge, this is the first study conducted in China to examine the performance of the DT including both inpatient and outpatient among heterogeneous cancer population.

We found that the DT demonstrated good discriminating accuracy $(\mathrm{AUC}=0.88)$ against $\mathrm{HADS}-\mathrm{T}$, which showed that the DT is an easier and acceptable tool. This finding is in agreement with earlier studies, where AUC ranged from 0.47 to 0.91 [8-12]. Against the HADS-T $(\geq 15)$, an optimal cutoff score of 4 was identified on the DT. This result was exactly in line with the current NCCN guidelines [5] and confirmed by other existing studies from different cultural backgrounds performed in Saudi Arabia [29], Korea [2], Italy [6], America [7], and China [19, 21]. Our result is also consistent with a study conducted in different clinical settings such as inpatient [24], outpatient [6, 7], and inpatient and outpatient combined [29] in heterogeneous and homogeneous cancer types [8, 9, 29]. Collectively, it is possible to infer that the cutoff score may not be influenced 
TABLE 2: Bivariate and multivariate analysis of the association between the distress thermometer (DT) score and the sociodemographic, clinical characteristics of patients, and the problem list domains.

\begin{tabular}{|c|c|c|c|c|c|}
\hline Demographic and clinical characteristics & No. of patients (\%) & $\mathrm{DT}<4(\%)$ & $\mathrm{DT} \geq 4(\%)$ & $\begin{array}{c}\text { Bivariate analysis } \\
P \text { value }\end{array}$ & $\begin{array}{c}\text { Multivariate analysis } \\
P \text { value }\end{array}$ \\
\hline Age (mean $\pm \mathrm{SD})$ & $54.4 \pm 11.2$ & & & & \\
\hline $\begin{array}{l}\text { Source } \\
\text { Inpatients } \\
\text { Outpatients } \\
\end{array}$ & $\begin{array}{l}784(52.4) \\
712(47.6) \\
\end{array}$ & $\begin{array}{l}328(41.8) \\
472(66.3)\end{array}$ & $\begin{array}{l}456(58.2) \\
240(33.7) \\
\end{array}$ & $<0.001^{* *}$ & 0.07 \\
\hline $\begin{array}{l}\text { Gender } \\
\text { Male } \\
\text { Female } \\
\end{array}$ & $\begin{array}{l}729(48.7) \\
767(51.3) \\
\end{array}$ & $\begin{array}{l}403(50.4) \\
397(49.6) \\
\end{array}$ & $\begin{array}{l}326(46.8) \\
370(53.2) \\
\end{array}$ & 0.17 & \\
\hline $\begin{array}{l}\text { Marital status } \\
\text { Married } \\
\text { Unmarried }^{\mathrm{a}} \\
\end{array}$ & $\begin{array}{c}1408(94.1) \\
88(5.9)\end{array}$ & $\begin{array}{c}750(53.3) \\
50(56.8)\end{array}$ & $\begin{array}{c}658(46.7) \\
38(43.2)\end{array}$ & 0.51 & \\
\hline $\begin{array}{l}\text { Education level } \\
\text { Junior high school or less } \\
\text { More than junior high school }\end{array}$ & $\begin{array}{l}847(56.6) \\
649(43.4) \\
\end{array}$ & $\begin{array}{l}412(48.6) \\
388(59.8)\end{array}$ & $\begin{array}{l}435(51.4) \\
261(40.2)\end{array}$ & $<0.001^{* *}$ & $0.01^{*}$ \\
\hline $\begin{array}{l}\text { Employment } \\
\text { Farmer } \\
\text { Others }\end{array}$ & $\begin{array}{c}490(32.8) \\
1006(67.2)\end{array}$ & $\begin{array}{l}223(45.5) \\
577(57.4)\end{array}$ & $\begin{array}{l}267(54.5) \\
429(42.6) \\
\end{array}$ & $<0.001^{* *}$ & 0.48 \\
\hline $\begin{array}{l}\text { Monthly income (RMB) } \\
\quad<3000 \\
>3000 \\
\end{array}$ & $\begin{array}{c}1062(71.0) \\
434(29.0)\end{array}$ & $\begin{array}{l}522(49.2) \\
260(59.9) \\
\end{array}$ & $\begin{array}{l}540(50.8) \\
174(40.1)\end{array}$ & $0.002^{*}$ & 0.28 \\
\hline $\begin{array}{l}\text { Diagnosis } \\
\text { Known } \\
\text { Unknown }\end{array}$ & $\begin{array}{c}1345(89.9) \\
151(10.1)\end{array}$ & $\begin{array}{c}732(54.4) \\
68(45.0)\end{array}$ & $\begin{array}{l}613(45.6) \\
83(55.0)\end{array}$ & $0.02^{*}$ & $0.02^{*}$ \\
\hline $\begin{array}{l}\text { Exercise } \\
\text { Lack (<150 } \mathrm{min} / \text { week }) \\
\text { Often }(>150 \mathrm{~min} / \text { week })\end{array}$ & $\begin{array}{c}1010(67.5) \\
486(32.5)\end{array}$ & $\begin{array}{l}441(43.7) \\
359(73.9)\end{array}$ & $\begin{array}{l}569(56.3) \\
127(26.1)\end{array}$ & $<0.001^{* *}$ & $<0.001^{* *}$ \\
\hline $\begin{array}{l}\text { Disease status } \\
\text { Complete remission } \\
\text { Active disease } \\
\end{array}$ & $\begin{array}{c}289(19.3) \\
1207(80.7)\end{array}$ & $\begin{array}{l}222(76.8) \\
578(47.9)\end{array}$ & $\begin{array}{l}67(23.2) \\
629(52.1) \\
\end{array}$ & $<0.001^{* *}$ & $0.001^{*}$ \\
\hline $\begin{array}{l}\text { Type of cancer } \\
\text { Lung } \\
\text { Digestive } \\
\text { Gynecological } \\
\text { Breast } \\
\text { Head and neck } \\
\text { Urogenital } \\
\text { Hematological } \\
\text { Bone and soft tissue } \\
\end{array}$ & $\begin{array}{c}503(33.6) \\
414(27.7) \\
163(10.9) \\
156(10.4) \\
107(7.2) \\
69(4.6) \\
63(4.2) \\
21(1.4) \\
\end{array}$ & $\begin{array}{c}250(49.7) \\
212(51.2) \\
104(63.8) \\
85(54.5) \\
55(51.4) \\
44(63.8) \\
39(61.9) \\
11(52.4) \\
\end{array}$ & $\begin{array}{cc}253 & (50.3) \\
202 & (48.8) \\
59 & (36.2) \\
71 & (45.5) \\
52 & (48.6) \\
25 & (36.2) \\
24 & (38.1) \\
10 & (47.6) \\
\end{array}$ & $\begin{array}{c}\mathbf{0 . 0 3}^{*} \\
0.27 \\
\mathbf{0 . 0 0 5}^{*} \\
0.78 \\
0.65 \\
0.79 \\
0.17 \\
0.91 \\
\end{array}$ & $\begin{array}{l}0.85 \\
0.91\end{array}$ \\
\hline $\begin{array}{l}\text { Stage of cancer } \\
\text { Advance } \\
\text { Others } \\
\end{array}$ & $\begin{array}{l}576(38.5) \\
920(61.5) \\
\end{array}$ & $\begin{array}{l}234(40.6) \\
566(61.5) \\
\end{array}$ & $\begin{array}{l}342(59.4) \\
354(38.5) \\
\end{array}$ & $<0.001^{* *}$ & $<0.001^{* *}$ \\
\hline $\begin{array}{l}\text { Treatment received } \\
\text { Combined treatment } \\
\text { Single treatment }\end{array}$ & $\begin{array}{l}834(55.7) \\
662(44.3)\end{array}$ & $\begin{array}{l}436(52.3) \\
364(55.0)\end{array}$ & $\begin{array}{l}398(47.7) \\
298(45.0)\end{array}$ & 0.29 & \\
\hline $\begin{array}{l}\text { Months since diagnosis } \\
<6 \text { months } \\
>6 \text { months }\end{array}$ & $\begin{array}{l}816(54.5) \\
680(45.5) \\
\end{array}$ & $\begin{array}{l}431(52.8) \\
369(54.3) \\
\end{array}$ & $\begin{array}{l}385(47.2) \\
311(45.7)\end{array}$ & 0.57 & \\
\hline Practical problem & $894(59.8)$ & $374(41.8)$ & $520(58.2)$ & $<0.001^{* *}$ & 0.12 \\
\hline Family problem & $464(31.0)$ & $176(37.9)$ & $288(62.1)$ & $<0.001^{* *}$ & 0.32 \\
\hline Emotional problem & $1064(71.1)$ & $176(37.9)$ & $288(62.1)$ & $<0.001^{* *}$ & $<0.001^{* *}$ \\
\hline Physical problem & $1174(78.5)$ & $503(42.8)$ & $671(57.2)$ & $<0.001^{* *}$ & $<0.001^{* *}$ \\
\hline $\mathrm{DT}($ mean $\pm \mathrm{SD})$ & $3.3 \pm 2.6$ & & & & \\
\hline
\end{tabular}




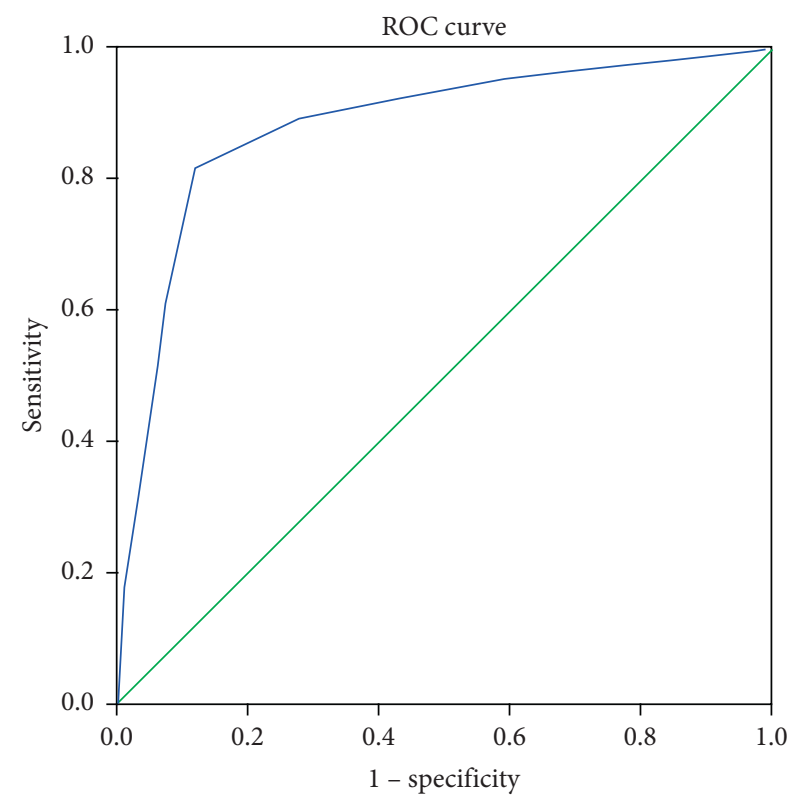

FIGURE 1: Receiver operating characteristic (ROC) curve of the distress thermometer (DT) score against the Hospital Anxiety and Depression Scales-Total (HADS-T) cutoff score. The area under the ROC curve (AUC) was 0.88 .

by geography, cultural issues, and screening settings but may depend on the disease "cancer" itself. These findings provide more evidence in generalizing the DT cutoff score across different cancer populations in different clinical settings.

However, some studies found higher cutoff scores in outpatient [1], lymphoma, [12], intracranial tumor, [14], shortly after breast cancer diagnosis [15], and advanced cancer inpatient with pain [22]. It is difficult to explain the exact cause for differences in cutoff scores between studies. Perception of PD can depend on an individual patient, which may differ with the course of cancer illness, treatment, and its specific physical problems. The DT has been translated from the English language, and there is no universal translating instrument that can exactly substitute the word "distress." Additionally, different translated phrases have yielded different cutoff scores in the same region of study [11]. There is no common method for selecting the cutoff score among the studies. All these factors may contribute for varying cutoff scores.

A cutoff score of 4 correctly detected 0.81 of distress cases (SE) and 0.88 of nondistress cases (SP). Among the previous studies, DT's sensitivity ranged from poor to excellent $(0.42-1.00)[8,20]$. The SE of this study was comparable to meta-analysis by Ma et al. (0.82) [9] and studies conducted in different geographical location including China (0.82 and 0.86) [11, 22], Korea (0.83) [2], and Spain (0.90) [13]. Regarding specificity, its value ranged from 0.36 to 0.98 and was comparable with the majority of previous studies $[2,8,11-13,15,22,29]$. Higher SE and SP of the DT can efficiently recognize a large proportion of patients with or without PD. The consistency of our result with available studies may be due to DT's nonstigmatizing nature and its unique thermometer-shaped visual analog scale. This makes it easier for the patients to choose the appropriate score corresponding to their perceived PD level.

We obtained a PPV of 0.87 and NPV of 0.82 at a cutoff score of 4, resulting in fewer false-positives (13\%) and falsenegative $(18 \%)$ rates. These are notable findings, which were not evaluated in most of the previous Chinese studies. Our results are comparable to studies performed across different countries, where PPV and NPV ranged from 0.35 to 95.8 and 0.68 to 97 , respectively $[8,15,22,29]$. These were important findings, which can prevent both over-misdiagnosis and underdiagnosis, reducing unnecessary patient volume, investigation, overtreatment, and financial burden. More importantly, UI+ (0.71) and UI- (0.73) also demonstrated that the DT had good accuracy in both ruling-in and ruling-out PD cases indicating that the DT has a good screening performance. Interestingly, the UI in our study was superior to Martinez et al. study [13]. The plausible cause for these discrepancies may be due to study methodology (i.e., BSI-18 vs. HADS) and differences in the characteristics of the included population.

The reported prevalence of distress in cancer patients around the globe ranges from $22.1 \%$ to $89.1 \%$ [3, 13, 29-31]. In our study, the incidence of PD was $46.5 \%$. Together with these results, we can infer that $\mathrm{PD}$ is a serious global problem among different cancer patients that needs routine monitoring, and providing appropriate management for PD is an urgent need.

Consistent with previous studies, sociodemographic factors such as lower education levels and advanced cancer stage were independently associated with PD in the present analysis [29, 32]. The well-educated populations are socially engaged and live healthier and longer because they have higher cognitive skills such as reading, writing, thinking, reasoning, problem solving, and possess strong decision power [33]. Whereas populations with lower educational backgrounds might have low socioeconomic status and limited access to available resources. All these factors may add stress in life causing PD. Diaz-Frutos et al. found that advanced or terminal stage patients were hopeless and emotionally disturbed [3]. Moreover, the possible cause for PD might be the thought of death, which is fear-provoking and painful. Also, in this study, patients with active disease status were at a greater risk of PD. During the active disease, patients may receive a series of anticancer treatments (surgery, chemotherapy, radiation-therapy, and biological therapy). These have several adverse effects, which might increase PD. Hence, while screening, healthcare professionals should prioritize vulnerable patients groups such as lower education levels, advanced cancer stage, and active disease status, which could be helpful for PD prevention.

Patients who know their diagnosis have less distress and a better quality of life $[34,35]$. We noted a similar finding where patients knowing their diagnosis were less likely to be at risk of PD. Nondisclosure of the diagnosis is the most common problem in cancer caring [16]. Disclosure may help patient to understanding the true situation of the disease that might lower the disbelief and hopelessness about their disease conditions. Awareness of diagnosis may enable them to cope with their true conditions and in turn improve patient satisfaction with care. The appropriate approach of disclosure could be a valuable support in cancer management. 
TABle 3: Sensitivity, specificity, Youden index, positive predictive value, negative predictive value, and clinical utility index of each distress thermometer (DT) cutoff score against the HADS-T scale.

\begin{tabular}{|c|c|c|c|c|c|c|c|}
\hline DT cut off score & Sensitivity & Specificity & Youden index & PPV & NPV & $\mathrm{UI+}$ & UI- \\
\hline \multicolumn{8}{|l|}{ Against HADS-T } \\
\hline $0 / 1$ & 0.95 & 0.40 & 0.35 & 0.61 & 0.90 & 0.58 & 0.36 \\
\hline $1 / 2$ & 0.93 & 0.52 & 0.45 & 0.66 & 0.88 & 0.61 & 0.46 \\
\hline $2 / 3$ & 0.89 & 0.72 & 0.61 & 0.76 & 0.87 & 0.68 & 0.63 \\
\hline $3 / 4^{\dagger}$ & 0.81 & 0.88 & 0.70 & 0.87 & 0.82 & 0.71 & 0.73 \\
\hline $4 / 5$ & 0.60 & 0.92 & 0.53 & 0.89 & 0.70 & 0.54 & 0.65 \\
\hline $5 / 6$ & 0.34 & 0.96 & 0.30 & 0.90 & 0.59 & 0.31 & 0.57 \\
\hline $6 / 7$ & 0.22 & 0.98 & 0.20 & 0.93 & 0.55 & 0.20 & 0.55 \\
\hline $7 / 8$ & 0.13 & 0.99 & 0.12 & 0.94 & 0.53 & 0.12 & 0.52 \\
\hline $8 / 9$ & 0.05 & 0.99 & 0.56 & 0.95 & 0.51 & 0.05 & 0.51 \\
\hline $9 / 10$ & 0.03 & 0.99 & 0.03 & 0.96 & 0.50 & 0.03 & 0.50 \\
\hline
\end{tabular}

HADS-T, Hospital Anxiety and Depression Scale-Total; PPV, positive predictive value; NPV, negative predictive value; positive utility index (UI+), sensitivity $\times$ PPV; negative utility index (UI-), specificity $\times$ NPV; Youden index, sensitivity + specificity- $1 .{ }^{\dagger}$ Bold values signify the balanced cutoff point with the highest Youden index.

TABLE 4: Risk factors for distress based on demographic, clinical variables, and problem list domains.

\begin{tabular}{|c|c|c|c|}
\hline Variables & $\begin{array}{l}\text { Odd } \\
\text { ratio }\end{array}$ & $\begin{array}{l}\text { 95\% confidence } \\
\text { interval }\end{array}$ & $P$ Value \\
\hline Source of patients & 1.29 & $0.972-1.732$ & 0.07 \\
\hline Diagnosis known & 0.64 & $0.435-0.951$ & $0.02^{*}$ \\
\hline $\begin{array}{l}\text { Lower education } \\
\text { levels }\end{array}$ & 1.39 & $1.060-1.825$ & $0.01^{*}$ \\
\hline Less income & 1.17 & $0.875-1.567$ & 0.28 \\
\hline Active disease status & 1.82 & $1.274-2.619$ & $0.001^{*}$ \\
\hline $\begin{array}{l}\text { Advanced cancer } \\
\text { stage }\end{array}$ & 1.85 & $1.424-2.405$ & $<0.001^{* *}$ \\
\hline Lung cancer & 1.02 & $0.783-1.344$ & 0.85 \\
\hline Gynecological cancer & 0.97 & $0.630-1.514$ & 0.91 \\
\hline Lack of exercise & 3.03 & $2.307-3.989$ & $<0.001^{* *}$ \\
\hline Practical problems & 1.25 & $0.941-1.684$ & 0.12 \\
\hline Family problems & 1.15 & $0.871-1.523$ & 0.32 \\
\hline Emotional problems & 3.54 & $2.540-4.942$ & $<0.001^{* *}$ \\
\hline Physical problems & 8.62 & $5.468-13.594$ & $<0.001^{* *}$ \\
\hline
\end{tabular}

Patients with a lack of physical exercise are strongly associated with higher PD [36]. The randomized controlled trial by Chen et al. mentioned that exercise habits are beneficial in relieving anxiety and depression [37]. Major health organization recommend that cancer patients should have at least $150 \mathrm{~min}$ of moderate-intensity or $75 \mathrm{~min}$ of high-intensity exercise combined with a minimum of two strengthening exercises sessions weekly [38]. Our study also demonstrated that lack of exercise was a risk factor for PD. Thus, exercise can be considered as a natural, safe, costeffective, and nonpharmacological alternative treatment to reduce cancer-specific $\mathrm{PD}$. Therefore, regular exercise might be worth recommending.

In our study, emotional and physical problems of the PL were strongly associated (exhibited high odd ratios and highly significant $P$ value) with PD. This was consistent within Chinese studies (i.e., lymphoma and advanced cancer with pain) and a Saudi Arabic study in mixed cancer patients $[12,22,29]$. This finding adds further evidence that emotional and physical problems may be independent of the ethnic group. Factors such as age, gender, marital status, occupation, time since diagnosis, cancer type, and treatment were not associated with distress and are consistent with previous studies $[22,29]$.

Despite the higher response rates and larger population size from two different clinical settings (inpatient and outpatient), our study had some limitations. First, there exists a possible selection bias because this was a single center cross-sectional study. Also, regarding DT validation, we only selected the HADS criteria, and diagnostic interviews were not performed, which may result in the incomplete assessment of the mental status of participants. Furthermore, well-designed, cross cultural studies are needed to validate our findings.

\section{Conclusions}

The prevalence of PD is high in Chinese cancer patients. DT with a cutoff score of 4 is a comprehensive, appropriate, and practical initial screener for PD in heterogeneous cancer patients. Lower education levels, advanced cancer stage, active disease status, nondisclosure of diagnosis, lack of exercise, and emotional and physical problems are the predicting factors that should be considered together for effective management of PD in such population.

\section{Data Availability}

The data used to support this study are included within the article.

\section{Conflicts of Interest}

The authors declare that they have no conflicts of interest.

\section{Authors' Contributions}

Sudip Thapa and Sun Huihui contributed equally to this work. 


\section{References}

[1] H. A. Lim, R. Mahendran, J. Chua, C.-X. Peh, S.-E. Lim, and E.-H. Kua, "The Distress thermometer as an ultra-short screening tool: a first validation study for mixed-cancer outpatients in Singapore," Comprehensive Psychiatry, vol. 55, no. 4, pp. 1055-1062, 2014.

[2] E.-J. Shim, Y.-W. Shin, H. J. Jeon, and B.-J. Hahm, "Distress and its correlates in Korean cancer patients: pilot use of the distress thermometer and the problem list," Psycho-Oncology, vol. 17, no. 6, pp. 548-555, 2008.

[3] D. Diaz-Frutos, E. Baca-Garcia, J. García-Foncillas, and J. López-Castroman, "Predictors of psychological distress in advanced cancer patients under palliative treatments," European Journal of Cancer Care, vol. 25, no. 4, pp. 608-615, 2016.

[4] L. E. Carlson, A. Waller, and A. J. Mitchell, "Screening for distress and unmet needs in patients with cancer: review and recommendations," Journal of Clinical Oncology, vol. 30, no. 11, pp. 1160-1177, 2012.

[5] J. C. Holland, B. Andersen, W. S. Breitbart et al., "Distress management," Journal of the National Comprehensive Cancer Network, vol. 11, no. 2, pp. 190-209, 2013.

[6] L. Grassi, C. Johansen, M. A. Annunziata et al., "Screening for distress in cancer patients," Cancer, vol. 119, no. 9, pp. 1714-1721, 2013.

[7] P. B. Jacobsen, K. A. Donovan, P. C. Trask et al., "Screening for psychologic distress in ambulatory cancer patients," Cancer, vol. 103, no. 7, pp. 1494-1502, 2005.

[8] K. A. Donovan, L. Grassi, H. L. McGinty, and P. B. Jacobsen, "Validation of the distress thermometer worldwide: state of the science," Psycho-Oncology, vol. 23, no. 3, pp. 241-250, 2014.

[9] X. Ma, J. Zhang, W. Zhong et al., "The diagnostic role of a short screening tool-the distress thermometer: a meta-analysis," Supportive Care in Cancer, vol. 22, no. 7, pp. 1741-1755, 2014.

[10] A. Cutillo, E. O’Hea, S. Person, D. Lessard, T. Harralson, and E. Boudreaux, "The distress thermometer: cutoff points and clinical use," Oncology Nursing Forum, vol. 44, no. 3, pp. 329-336, 2017.

[11] B. Zheng, P. Du, T. Yi et al., "Effects of two translated phrases of distress thermometer on screening distress in Chinese cancer patients: a comparative study," Journal of Clinical Nursing, vol. 28, no. 5-6, pp. 828-835, 2018.

[12] Y. Wang, L. Zou, M. Jiang, Y. Wei, and Y. Jiang, "Measurement of distress in Chinese inpatients with lymphoma," Psycho-Oncology, vol. 22, no. 7, pp. 1581-1586, 2013.

[13] P. Martinez, M. J. Galdon, Y. Andreu, and E. Ibanez, "The Distress Thermometer in Spanish cancer patients: convergent validity and diagnostic accuracy," Supportive Care in Cancer, vol. 21, no. 11, pp. 3095-3102, 2013.

[14] S. Goebel and H. M. Mehdorn, "Measurement of psychological distress in patients with intracranial tumours: the NCCN distress thermometer," Journal of Neuro-Oncology, vol. 104, no. 1, pp. 357-364, 2011.

[15] F. K. Ploos van Amstel, J. Tol, K. H. Sessink, W. T. A. van der Graaf, J. B. Prins, and P. B. Ottevanger, "A specific distress cutoff score shortly after breast cancer diagnosis," Cancer Nursing, vol. 40, no. 3, pp. E35-E40, 2017.

[16] C. Y. Tse, A. Chong, and S. Y. Fok, "Breaking bad news: a Chinese perspective," Palliative Medicine, vol. 17, no. 4, pp. 339-343, 2003.
[17] S. S. Yeo, B. Meiser, K. Barlow-Stewart, D. Goldstein, K. Tucker, and M. Eisenbruch, "Understanding community beliefs of Chinese-Australians about cancer: initial insights using an ethnographic approach," Psycho-Oncology, vol. 14, no. 3, pp. 174-186, 2005.

[18] B. Huang, H. Chen, Y. Deng, T. Yi, Y. Wang, and Y. Jiang, "Diagnosis, disease stage, and distress of Chinese cancer patients," Annals of Translational Medicine, vol. 4, no. 4, p. 73, 2016.

[19] L.-L. Tang, Y.-N. Zhang, Y. Pang, H.-W. Zhang, and L.-L. Song, "Validation and reliability of distress thermometer in Chinese cancer patients," Chinese Journal of Cancer Research, vol. 23, no. 1, pp. 54-58, 2011.

[20] J. S. Hong and J. Tian, "Sensitivity and specificity of the Distress Thermometer in screening for distress in long-term nasopharyngeal cancer survivors," Current Oncology (Toronto, Ont.), vol. 20, no. 6, pp. e570-6, 2013.

[21] Y.-T. Deng, W.-N. Zhong, and Y. Jiang, "Measurement of distress and its alteration during treatment in patients with nasopharyngeal carcinoma," Head \& Neck, vol. 36, no. 8, pp. 1077-1086, 2014.

[22] B. Guan, K. Wang, Y. Shao et al., "The use of distress thermometer in advanced cancer inpatients with pain," PsychoOncology, vol. 28, no. 5, pp. 1004-1010, 2019.

[23] G.-L. Wang, S.-H. Hsu, A.-C. Feng et al., "The HADS and the DT for screening psychosocial distress of cancer patients in Taiwan," Psycho-Oncology, vol. 20, no. 6, pp. 639-646, 2011.

[24] Y.-J. Chiou, C.-Y. Lee, S.-H. Li, M.-Y. Chong, Y. Lee, and L.-J. Wang, "Screening for psychologic distress in Taiwanese cancer inpatients using the national comprehensive cancer network distress thermometer: the effects of patients' sex and chemotherapy experience," Psychosomatics, vol. 58, no. 5, pp. 496-505, 2017.

[25] A. S. Zigmond and R. P. Snaith, "The hospital anxiety and depression scale," Acta Psychiatrica Scandinavica, vol. 67, no. 6, pp. 361-370, 1983.

[26] I. Bjelland, A. A. Dahl, T. T. Haug, and D. Neckelmann, "The validity of the hospital anxiety and depression scale," Journal of Psychosomatic Research, vol. 52, no. 2, pp. 69-77, 2002.

[27] A. J. Mitchell, "Clinical Utility Index-a new method to calculate the clinical value of diagnostic \& screening tests: proof of concept study," Psycho-Oncology, vol. 19, no. 2, p. $686,2010$.

[28] J. C. Holland and B. D. Bultz, "The NCCN guideline for distress management: a case for making distress the sixth vital sign," Journal of the National Comprehensive Cancer Network, vol. 5, no. 1, pp. 3-7, 2007.

[29] F. D. Alosaimi, N. Abdel-Aziz, K. Alsaleh, R. AlSheikh, R. AlSheikh, and A. Abdel-Warith, "Validity and feasibility of the arabic version of distress thermometer for saudi cancer patients," PLoS One, vol. 13, no. 11, Article ID e0207364, 2018.

[30] Y.-J. Chiou, N.-M. Chiu, L.-J. Wang et al., "Prevalence and related factors of psychological distress among cancer inpatients using routine distress thermometer and Chinese health questionnaire screening," Neuropsychiatric Disease and Treatment, vol. 12, pp. 2765-2773, 2016.

[31] J. Xie, S. Ding, S. He, Y. Duan, K. Yi, and J. Zhou, "A prevalence study of psychosocial distress in adolescents and young adults with cancer," Cancer Nursing, vol. 40, no. 3, pp. 217-223, 2017.

[32] S. J. Kim, S. Y. Rha, S. K. Song et al., "Prevalence and associated factors of psychological distress among Korean cancer patients," General Hospital Psychiatry, vol. 33, no. 3, pp. 246-252, 2011. 
[33] D. P. Baker, J. Leon, E. G. Smith Greenaway, J. Collins, and M. Movit, "The education effect on population health: a reassessment," Population and Development Review, vol. 37, no. 2, pp. 307-332, 2011.

[34] Y. H. Yun, Y. C. Kwon, M. K. Lee et al., "Experiences and attitudes of patients with terminal cancer and their family caregivers toward the disclosure of terminal illness," Journal of Clinical Oncology, vol. 28, no. 11, pp. 1950-1957, 2010.

[35] A. Costantini, L. Grassi, A. Picardi et al., "Awareness of cancer, satisfaction with care, emotional distress, and adjustment to illness: an Italian multicenter study," PsychoOncology, vol. 24, no. 9, pp. 1088-1096, 2015.

[36] G. Zhao, C. Li, J. Li, and L. S. Balluz, "Physical activity, psychological distress, and receipt of mental healthcare services among cancer survivors," Journal of Cancer Survivorship, vol. 7, no. 1, pp. 131-139, 2013.

[37] H.-M. Chen, C.-M. Tsai, Y.-C. Wu, K.-C. Lin, and C.-C. Lin, "Randomised controlled trial on the effectiveness of homebased walking exercise on anxiety, depression and cancerrelated symptoms in patients with lung cancer," British Journal of Cancer, vol. 112, no. 3, pp. 438-445, 2015.

[38] C. L. Rock, C. Doyle, W. Demark-Wahnefried et al., "Nutrition and physical activity guidelines for cancer survivors," CA: A Cancer Journal for Clinicians, vol. 62, no. 4, pp. 243274, 2012. 